\title{
OLIGÔMEROS E POLÍMEROS DERIVADOS DO TIOFENO: SÍNTESE E APLICAÇÕES
}

\author{
Marcos Roberto de Abreu Alves, Hállen Daniel Rezende Calado, Tulio Matencio e Claudio Luis Donnici*\# \\ Departamento de Química, Instituto de Ciências Exatas, Universidade Federal de Minas Gerais, Av. Antônio Carlos, 662, \\ 31270-901 Belo Horizonte - MG, Brasil
}

Recebido em 24/3/10; aceito em 27/8/10; publicado na web em 25/10/10

\begin{abstract}
THIOPHENE-BASED OLIGOMERS AND POLYMERS: SYNTHESES AND APPLICATIONS. In this review we summarize recent synthetic investigations about the preparation of oligothiophenes and polythiophenes, the most important $\pi$-conjugated organic materials for applications in electrochromic and electroluminescent devices. It is showed that many interesting and novel functionalized oligothiophenes have been synthesized by convenient coupling strategies (Heck, Kumada, Negishi, Suzuki, Stille and Ullmann) and oxidative coupling methods. Synthesis of polythiophenes are also presented and described according to chemical and electrochemical polymerization methodologies. The description of these noteworthy synthetic methods illustrates how important and promising are the interdisciplinary approaches in the obtaining of oligothiophenes and polythiophenes.
\end{abstract}

Keywords: oligomeric and polymeric thiophenes; syntheses; conjugated polymers.

\section{INTRODUÇÃO}

Os polímeros conjugados (PCs) são conhecidos como "metais sintéticos" devido a suas propriedades elétricas, magnéticas, eletrônicas e ópticas semelhantes aos dos metais; as propriedades de um polímero convencional (flexibilidade, processabilidade e formação de filmes finos, boa estabilidade térmica, etc.) e as propriedades de um semicondutor combinadas em um único material resultam em polímeros para aplicação no campo da eletrônica orgânica. A incontestável importância científica atual desta classe de materiais pode ser percebida pela concessão do Prêmio Nobel de Química de 2000 para Heeger, McDiarmid e Shirakawa por suas pesquisas com PCs. ${ }^{1}$ É digno de nota que, quando estes materiais são estimulados eletricamente, podem ter sua cor variada de forma reversível ou mesmo emitir luz visível, o que possibilita a sua aplicação em diversos dispositivos eletrocrômicos ${ }^{2}$ ou diodos emissores de luz orgânicos (OLEDs - Organic Light Emission Diodes). Dentre outras possibilidades de aplicação, pode-se citar o desenvolvimento de condutores elétricos, células fotovoltaicas poliméricas, transistores orgânicos, ${ }^{3,4}$ anticorrosivos, ${ }^{5,6}$ materiais eletrocrômicos, ${ }^{7}$ baterias recarregáveis, ${ }^{8}$ etc.

Em meio aos diversos PCs pesquisados para o desenvolvimento dos dispositivos eletrônicos orgânicos, tais como politiofenos (1), polipirróis (2), polianilinas (3), ${ }^{9,10}$ polifenilenovinilenos $(\mathbf{4})^{11}$ (Figura 1), destacam-se os politiofenos e seus derivados, que são os materiais mais estudados nesta área. ${ }^{2} \mathrm{~A}$ possibilidade de aplicação dos politiofenos em dispositivos eletrocrômicos é conhecida desde $1983^{12-15} \mathrm{e}$, em 1986, com a primeira síntese descrita de polialquiltiofenos com processabilidade e projeção a nível industrial, surgia a prospecção do enorme escopo da aplicação destes materiais em dispositivos eletrônicos.

*e-mail: cdonnici@terra.com.br

\#Thanks a lot, Prof. Hans Viertler, for everything you taught me: a plenty of good chemistry, specially organic chemistry and electrochemistry... Thanks for the good examples to be followed and the mistakes and bad things to be avoided... and finally citing Carl Gustav Jung as followed, thank you for helping me to transform myself in the chemist I am now... "The meeting of two personalities is like the contact of two chemical substances: if there is any reaction, both are transformed."
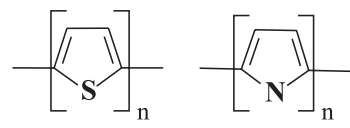

1 2
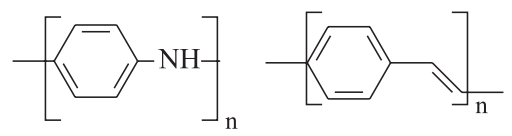

3

4

Figura 1. Estrutura química de alguns PCs

Apesar da obtenção de politiofeno e derivados ser bem conhecida, a importância da otimização dos métodos de preparação de PCs com a finalidade de se controlar as propriedades ópticas e eletrônicas tem sido sempre um ponto de interesse geral por parte de diversos pesquisadores. ${ }^{2,16,17}$ Neste âmbito, esses pesquisadores vêm considerando que a utilização de unidades tiofênicas oligoméricas, para posterior polimerização química ou eletroquímica, pode conduzir a materiais com menor grau de defeitos estruturais e, consequentemente, maior conjugação, favorecendo sua aplicabilidade em dispositivos ópticos pela maior regularidade do material., ${ }^{2,16,17}$

A condutividade dos PCs está associada à presença do sistema $\pi$ conjugado em sua estrutura, podendo passar de isolantes a condutores através de adição de substâncias denominadas dopantes. ${ }^{16}$ A capacidade dos PCs conduzir eletricidade está relacionada com a diferença de energia entre o orbital de maior energia ocupado (HOMO) e o orbital de menor energia desocupado (LUMO), valor energético conhecido como band gap, ou Lacuna de energia $\left(\mathrm{L}_{\mathrm{e}}\right)$. Assim sendo, quanto menor a diferença entre estes dois níveis de energia, maior será a possibilidade de o polímero formado apresentar boa condutividade (semicondutor). Uma menor $\mathrm{L}_{\mathrm{e}}$ pode ser conseguida através do aumento da conjugação da estrutura polimérica ou dopante. ${ }^{18}$ Uma das estratégias mais empregadas é a variação do padrão de substituição da cadeia lateral dos politiofenos, o que pode resultar na modulação planejada das propriedades eletrônicas do polímero, de modo a se obter compostos que, por exemplo, quando submetidos a um estímulo elétrico conduzam a várias colorações, indo do vermelho até o azul dependendo do substituinte no anel tiofênico. ${ }^{2}$ Assim, pode-e constatar a grande importância do controle dos diferentes métodos 
para obtenção sintética de oligômeros e de polímeros de tiofenos, pois variações estruturais moleculares e macromoleculares podem conduzir a diferentes propriedades dos materiais. ${ }^{19}$

Além dos importantes trabalhos de revisão sobre a síntese e a utilização de politiofenos já citados, ${ }^{2,16,17}$ podemos encontrar o trabalho enciclopédico sobre polímeros condutores com aplicações em nanotecnologia ${ }^{20} \mathrm{e}$, ainda, vários outros livros e artigos que tratam de oligo- e poli-tiofenos. ${ }^{21-38}$

No que tange, especificamente, à síntese química de oligo- e poli-tiofenos, podem-se citar metodologias sintéticas modernas, como as apresentadas no artigo de revisão de Anctil e colaboradores ${ }^{39} \mathrm{e}$ que já são bem conhecidas na literatura, ${ }^{40}$ para funcionalização de tiofenos por orto-metalação de acoplamento cruzado do tipo Suzuki (reações de acoplamento entre organoboranos e haletos de alquila catalisadas por paládio), Kumada (acoplamento entre haletos de alquenila/alquila e alquilmagnesianos catalisadas por complexos de níquel com fosfinas), Negishi (acoplamento entre haletos de alquenila/alquila e organometálicos de zinco, na presença de complexos de níquel/paládio com trifenilfosfinas) e Stille (acoplamento entre organoestânicos, haletos de alquenila/alquila, monóxido de carbono para geração de cetonas substituídas), ${ }^{40}$ todavia, neste artigo não são mostradas aplicações diretas da síntese de oligotiofenos. Babudri e colaboradores, em outro artigo de revisão, ${ }^{41}$ apresentam métodos de acoplamento sobre síntese de oligoenos tiofênicos mais complexos, tais como oligofenilenovinilenos, oligofenilenos, oligo-tiofenoarilenos e unidades oligo-tiofeno-antraquinonas. A minirrevisão de Yamamoto $^{42}$ relata somente a síntese de polímeros diversos, entre eles politiofenos, pelo uso de acoplamentos com compostos organometálicos e a correspondente formação de complexos metálicos com atividade catalítica, sem abordagem sintética específica para obtenção de oligotiofenos.

No que se refere exatamente a trabalhos de revisão sobre a obtenção de oligotiofenos por síntese química há importantes artigos, porém alguns são antigos, ${ }^{43}$ outros como, por exemplo, os artigos japoneses de Hotta e de Otsubo e Aso, ${ }^{44,45}$ não estão disponíveis em inglês. Há outro importante artigo a ser citado, o de Lukevics e colaboradores ${ }^{46}$ entretanto, apesar de citarem os métodos sintéticos mais conhecidos (Kumada, Negishi, Suzuki, Stille e Ullmann (acoplamento entre haletos de arila na presença de cobre)) não há citações de reações do tipo Heck (reação de haletos, especialmente iodetos, de arila na presença catalítica de paládio metálico e base nitrogenada de substituintes volumosos), nem uso de organoaluminatos, ${ }^{40}$ nem a descrição de métodos para síntese de politiofenos como citado neste artigo.

Neste trabalho de revisão são apresentados os principais métodos para obtenção química de oligotiofenos e obtenção química e eletroquímica de politiofenos. Particularmente, no caso dos oligotiofenos, importantes precursores para a obtenção de PCs com alto grau de conjugação, são abordados os métodos sintéticos de acoplamento (tipos Heck, Kumada, Negishi, Stille, Suzuki e Ullmann). Além disso, pretende-se chamar a atenção de químicos sintéticos - do Brasil e de países de língua portuguesa - para a necessidade da colaboração mútua imprescindível com os químicos de novos materiais na busca e desenvolvimento de novas metodologias de síntese mais eficientes. Nestas áreas tecnológicas de ponta, almeja-se a interdisciplinaridade para o desenvolvimento da habilidade para construção de moléculas e macromoléculas com estruturas e características específicas, que sejam adequadas para a obtenção das propriedades físicas, químicas e mecânicas desejadas para o desenvolvimento tecnológico de dispositivos óptico-eletrônicos cada vez melhores.

As referências correspondentes a cada metodologia de síntese foram selecionadas pela descrição clara e detalhada do procedimento experimental da síntese, com descrição de aplicações genéricas e comprovadas pela reprodutibilidade do método, encontradas em periódicos facilmente acessíveis. Em alguns casos o artigo foi selecionado pelo ineditismo e pela síntese relevante de moléculas singulares e de alto interesse. Cabe ressaltar que muitas das metodologias aqui apresentadas já foram empregadas por nosso grupo de pesquisa e obtivemos sucesso na execução das sínteses.

\section{OLIGÔMEROS BASEADOS EM TIOFENOS}

\section{Descrição histórica do avanço dos métodos de síntese para oligômeros do tiofeno e derivados}

Como já citado, oligotiofenos, ou $\alpha$-oligotiofenos têm sido utilizados na confecção de dispositivos ópticos, destacando-se seu uso como modelos de politiofenos no estudo de cinética de polimerização em eletrodos. ${ }^{47}$ Diversos são os métodos de preparo destes oligômeros, bem como o tipo e as características dos mesmos. Estes materiais podem ser produzidos através do acoplamento entre monômeros que apresentam (ou não) em sua estrutura substituintes que influenciam diretamente nas propriedades do material. Em geral, diversos dímeros, trímeros, tetrâmeros, entre outros, têm sido sintetizados de acordo com as propriedades almejadas.

Em 1950, Meisel e colaboradores ${ }^{48}$ reportaram o estudo da reação química utilizando ácido fosfórico como agente iniciador de tiofenos, e relataram a obtenção de um líquido que, na verdade, se tratava de mistura com a predominância de trímeros, uma menor quantidade de pentâmeros e traços de materiais diméricos, ou seja, o processo de acoplamento entre os monômeros era controlado. Este fato foi extremamente relevante, pois até então os polímeros obtidos a partir de tiofenos e derivados eram materiais amorfos e altamente insolúveis. $\mathrm{Na}$ verdade, o interesse por métodos de síntese que gerassem oligotiofenos com tamanhos específicos e com acoplamentos regiosseletivos surge após a descoberta, na década de 70, de que oligômeros derivados de tiofenos (di- e tri-tiofenos, 5 e 6, Figura 2) demonstravam atividades biológicas relevantes. ${ }^{49,50}$ Diante deste fato, Kagan e colaboradores, ${ }^{51,52}$ visando a obtenção de oligômeros com tamanhos específicos, com grau de pureza satisfatório e que pudessem apresentar propriedades biológicas, reportaram a obtenção de $\mathbf{6}$ através da ciclização do 1,4-ditienil1,3-butadiino (7) com sulfeto de hidrogênio, além de apresentarem a obtenção dos oligômeros $\alpha$-tetra-tiofeno (8) e $\alpha$-hepta-tiofeno (9) através da ciclização de derivados de 1,3-butadi-ino com sulfeto de sódio (Figura 3a). A metodologia de construção de oligômeros de tiofenos empregada mostrou-se muito interessante para a obtenção de produtos com números pares ou ímpares de unidades repetitivas, porém o método tende a se limitar com o aumento do tamanho da cadeia, devido ao rápido decréscimo da solubilidade com o aumento do peso molecular dos oligômeros. Os mesmos pesquisadores também reportaram, em 1983, ${ }^{53}$ um método de obtenção de oligômeros de tiofenos com acoplamentos seletivos (com 2 a 6 unidades repetitivas) através da utilização de reações de acoplamento de organometálico de lítio $\mathbf{1 0}$ com organoborato 11, que demonstrou ser uma ótima rota para se obter oligômeros regiorregulares com bons rendimentos (Figura 3b).

Outros pesquisadores, ${ }^{54-56}$ também na década de 80 , demonstraram a obtenção de oligômeros de tiofeno regiorregulares contendo três, quatro, cinco e seis unidades repetitivas (compostos 6, 8, 12

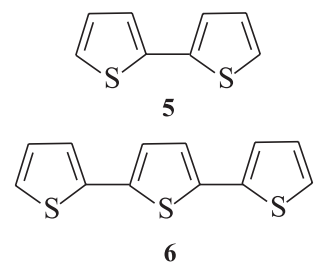

Figura 2. Estrutura química do di-tiofeno 5 e tri-tiofeno 6 


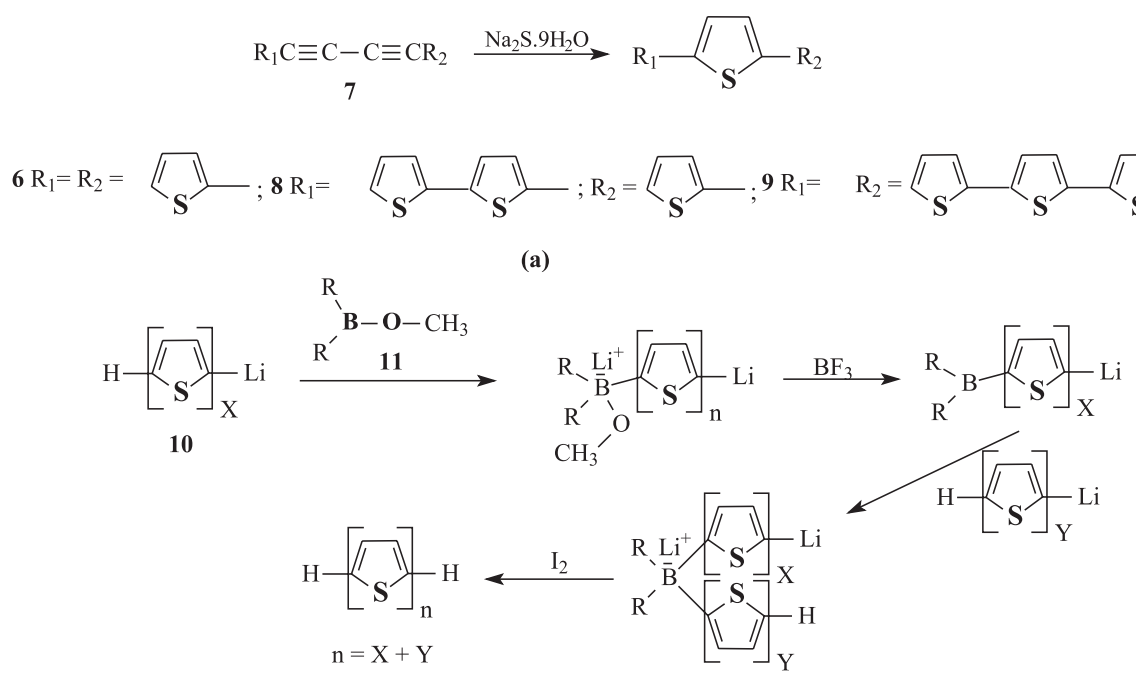

(b)

Figura 3. Esquema das rotas sintéticas utilizadas por Kagan et al. na obtenção de oligômeros de $\alpha$-tiofenos bem definidos: (a) ciclização de derivados de 1,3- butadi-ino utilizando sulfeto de sódio ${ }^{51,52}$ e (b) por acoplamento de $10 \mathrm{com} 11^{53}$

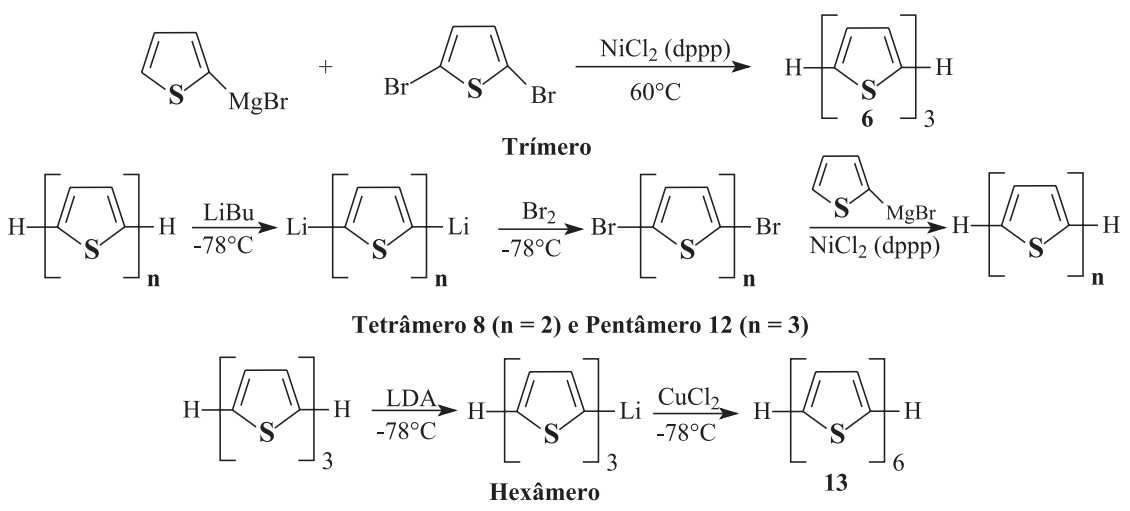

(b)

Figura 4. Rotas sintéticas utilizadas por Zhao e colaboradores ${ }^{56}$ na obtenção de oligômeros com três, quatro, cinco e seis unidades monoméricas

e 13, respectivamente) através do acoplamento (tipo Kumada) de organomagnésio de tiofeno com 2,5-dibromotiofeno, catalisado por complexo de níquel (Figura 4).

Em 1991, Wang e Hwang realizaram a síntese de oligômeros do tiofeno através de uma solução de tiofeno em álcool/água (2:1) na presença de $\mathrm{PdCl}_{4}^{2-}$ por $24 \mathrm{~h}$, o que resultou em compostos $\alpha, \alpha$ acoplados ditiofeno 5 (Figura 5) e tertiofeno 6, porém na forma de uma mistura (razão de 3:1). ${ }^{57}$ Katz e colaboradores ${ }^{58}$ reportaram a obtenção de hexatiofeno 13 através da dimerização de $\mathbf{6}$ utilizando-se de dois interessantes métodos: através da dimerização oxidativa com cloreto férrico em benzeno (Figura 6a) e, através da dimerização por acoplamento de 2-lítio derivados de $\mathbf{6}$ catalisados por cloreto cúprico (Figura 6b). Além deste oligômero 13, um tetrâmero 8 e um octâmero foram obtidos. Estes pesquisadores mostraram que o processo de acoplamento oxidativo com cloreto férrico resulta em materiais contaminados por ferro (cloreto férrico), devido à presença de defeitos na estrutura do material final. Mas, em relação ao acoplamento de derivados de lítio catalisado por cloreto cúprico, este apresenta baixa quantidade de metal, porém observou-se uma contaminação do material final (cerca de 25\% na obtenção de dímeros de 5 e $\mathbf{6}$ ). Uma alternativa proposta foi utilizar o acetilacetonato férrico no processo de acoplamento dos 2-lítio derivados que, após passar pelos processos de purificação descritos pelos autores, fornece oligômeros

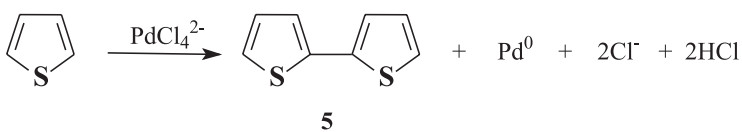

Figura 5. Síntese de dímeros de tiofeno através do emprego de $\mathrm{PdCl}_{4}^{2-}$ como catalisador $^{57}$

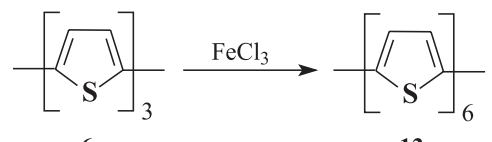

6

(a)

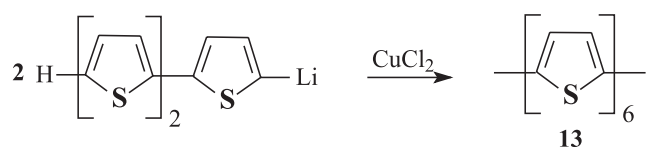

(b)

Figura 6. Síntese de hexâmeros através de acoplamentos utilizando (a) cloreto férrico e (b) cloreto cúprico ${ }^{58}$

com elevada pureza e com acoplamentos regiosseletivos.

Sone e colaboradores ${ }^{59}$ descreveram um método interessante e simples de obtenção de dímeros de 4-aril-2-clorotiofeno (14) (Figura 7). A obtenção de $\mathbf{1 4}$ é feita através da reação do 2,5-diclorotiofeno 
(15) com um derivado benzílico, na presença de cloreto de alumínio e com diclorometano como solvente. Após a obtenção de 14, os autores realizaram a formação de dímeros $\mathbf{1 4 a}$ e $\mathbf{1 4 b}$ através de duas rotas: autocondensação do monômero utilizando $\mathrm{AlCl}_{3}$ em diclorometano e, acoplamento (tipo Negishi) do $\mathbf{1 4}$ na presença de $\mathrm{NiCl}_{2}, \mathrm{PPh}_{3} \mathrm{e}$ $\mathrm{Zn}$ em N,N-dimetilformamida, que resulta em produtos com bons rendimentos (60 a 90\%).

Como mencionado, o aumento da cadeia dos $\alpha$-oligotiofenos não substituídos (número igual ou maior que sete unidades monoméricas) tende a diminuir sua solubilidade e a possibilidade de realização de diversos estudos, processamentos e aplicações. Esta limitação foi contornada com a adição de grupamentos alquilas na posição $\beta$ - (ou 3-) como ramificação na estrutura do oligômero, o que resultou em um importante favorecimento no avanço das pesquisas não só de oligômeros maiores, mas também na formação de polímeros de derivados de tiofeno solúveis. Tour e $\mathrm{Wu}^{60}$ realizaram a síntese de hexâmeros 16, heptâmeros 17 e octâmero 18 (Figura 8) através do acoplamento de outros oligômeros de cadeia menor tendo um grupo metila substituído na posição $\beta$ - do anel tiofênico, o que favoreceu a obtenção de $\alpha$-oligômeros solúveis. Para isso, os autores utilizaram métodos como o de formação de organomagnésio de tiofeno e posterior acoplamento utilizando níquel como catalisador (tipo Kumada), e acoplamentos com uso de organoborato e sais de paládio (tipo Suzuki) que forneceram oligômeros simétricos e regiorregulares com bons rendimentos. Hoeve e colaboradores ${ }^{61}$ obtiveram dois $\alpha$-oligômeros contendo grupos alquilas de quatro e doze átomos de carbono substituídos (Figura 8, oligômero 19) na posição $\beta$ - contendo onze unidades monoméricas, através de um método alternativo aos descritos anteriormente, utilizando-se da ciclização de dicetonas através do reagente de Lawesson para a formação dos anéis do tiofeno.

Hassan e colaboradores ${ }^{62}$ reportaram a obtenção de oligômeros substituídos bem definidos utilizando o paládio como catalisador. Assim, para a obtenção do tetrâmero 3',4"-dioctil-5,5'"-dicloro$2,2^{\prime}: 5^{\prime}, 2^{\prime \prime}: 5 ", 2^{\prime \prime \prime}$-tetratienil (20) utilizaram três rotas. A primeira foi realizada utilizando-se reações do tipo Heck de derivados iodados (Figura 9a). A segunda rota utilizou reações do tipo Heck, porém com derivados bromados (Figura 9b). O rendimento do produto final entre a primeira rota e a segunda não apresentou diferença satisfatória (61 e $65 \%$, respectivamente), porém o segundo método tem a vantagem de eliminar a necessidade da utilização do óxido de mercúrio para a realização da iodação, já que o mesmo é altamente tóxico. A terceira rota foi através de uma reação também do tipo Heck, (Figura 9c), com o acoplamento do 5-iodo-3-octil-5' -cloro-2,2'-bis-tiofeno na presença de base orgânica ((i-Pr) $\left.{ }_{2} \mathrm{EtN}\right)$ no lugar do carbonato de potássio, o que proporcionou um rendimento de $83 \%$ do tetrâmero 20.

A observação de que a rotação da estrutura oligomérica ao redor de ligações simples pode afetar significativamente sua conjugação

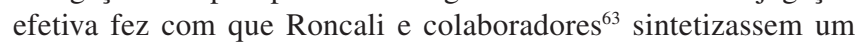
oligômero (21, Figura 10) com estrutura rígida, para avaliar esta observação. As análises realizadas demonstraram que o mesmo apresentou mudanças significativas nas propriedades eletrônicas e ópticas do material, bem como uma redução considerável na $\mathrm{L}_{\mathrm{e}}$ quando comparado a um análogo com possibilidade de rotação $(1,8$ para 1,4 eV). Apesar desta melhora, os autores deixaram em discussão<smiles>Clc1ccc(Cl)s1</smiles>

15<smiles>[R]c1ccccc1</smiles>

Ar-H<smiles>COC(C)(C)C(C)(C)C</smiles>

Figura 7. Rota sintética para dímeros do 14: (a) autocondensação utilizando $\mathrm{AlCl}_{3}$ em solução de diclorometano e (b) acoplamento na presença de $\mathrm{NiCl}$, $\mathrm{PPh}_{3}$ e Zn em n,n-dimetilformamida ${ }^{59}$<smiles>Cc1cc(-c2cc(C)c(-c3cc(C)c(-c4ccc(S(C)(C)C)s4)s3)s2)sc1-c1ccc([SiH3])s1</smiles><smiles>Cc1cc(-c2ccc(-c3cc(C)c(-c4sc(-c5cc(C)c(-c6ccc(S(C)(C)C)s6)s5)cc4C)s3)s2)sc1-c1ccc(S(C)(C)C)s1</smiles><smiles>Cc1ccc(-c2sc(-c3sc(-c4ccc(-c5ccc(-c6cc(C)c(-c7cc(C)c(-c8ccc(S(C)(C)C)s8)s7)s6)s5)s4)cc3C)cc2C)s1</smiles>

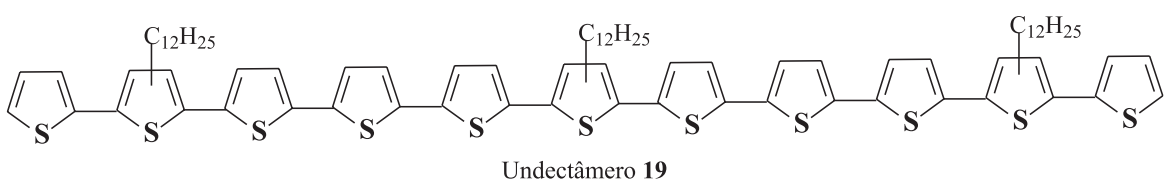

(b)

Figura 8. Estrutura química dos oligômeros hexâmeros (16), heptâmeros (17) e octâmero (18) obtidos por Tour e Wu ${ }^{60}$ e um oligômero com 11 unidades monoméricas (19) obtido por Hoeve e colaboradores ${ }^{61}$ 


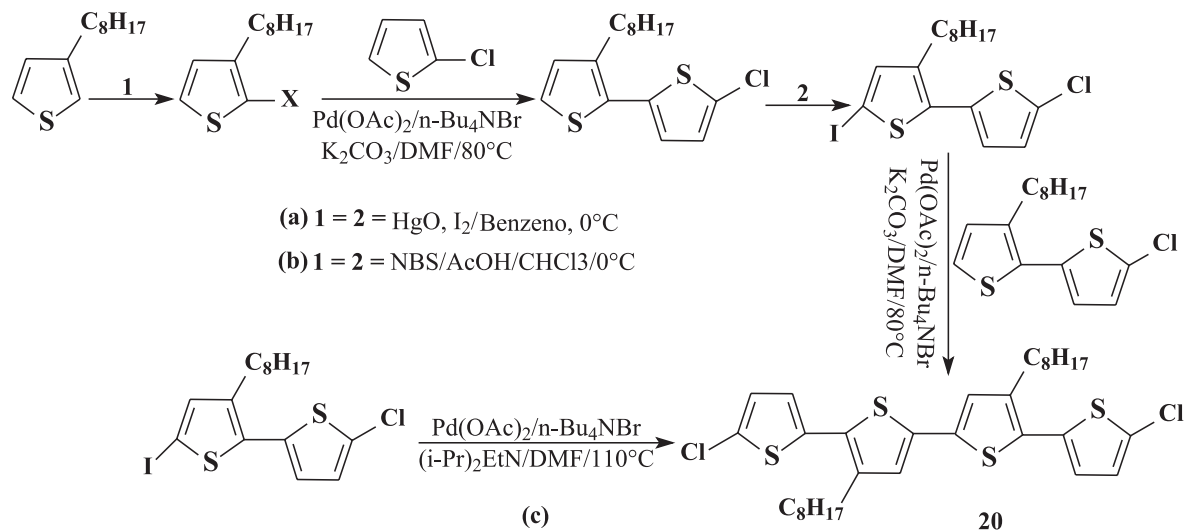

Figura 9. Síntese do oligômero 20 através de (a) reações do tipo Heck com derivado iodado e carbonato, (b) reações do tipo Heck com derivado bromado e carbonato (c) reação do tipo Heck clássica com base volumosa ${ }^{62}$

esta observação, já que a necessidade de obter materiais com boas propriedades eletrônicas e processáveis é contrária à obtenção de materiais rígidos, o que desfavorece seu processamento. $\mathrm{O}$ que se pode fazer, em relação a este conflito de questões ideais, é não preferir por uma ou outra e sim unir estes dois princípios na tentativa de se obter materiais com boas propriedades eletrônicas e mesmo ópticas sem abrir mão de sua processabilidade, sendo a copolimerização um caminho promissor no desenvolvimento de novos materiais.

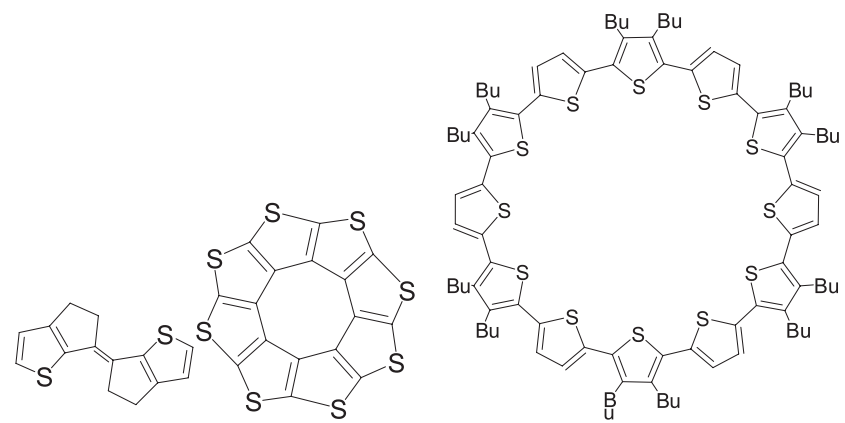

Figura 10. Estrutura química do oligômero com estrutura rígida 21 obtido por Roncoli e colaboradores, ${ }^{63}$ Sulflower ${ }^{64} 22$ e dos macrocíclicos $\pi$-conjugados de tiofenos ${ }^{65} 23$

A síntese de oligotiofenos de estrutura molecular complexa e singular mostra como a habilidade para construção de moléculas com características especiais pode conduzir à obtenção de novas estruturas diferentes e únicas como o sulflower (coroa de tiofeno, 22, Figura 10). ${ }^{64}$ Além disso, tem-se obtido oligômeros macrocíclicos $\pi$-conjugados de tiofenos $(\mathbf{2 3})^{65}$ que, devido ao seu alto grau de conjugação, poderão ser aplicados em dispositivos eletrônicos orgânicos, como ressaltam os autores.
Outra aplicação singular da síntese de novos tipos de oligotiofenos refere-se aos estudos da obtenção de novos polímeros lineares conjugados com politiofenos e fulereno-C60, para obtenção de materiais especiais para construção de células fotovoltáicas. ${ }^{66,67}$ Cabe ressaltar que a aplicabilidade de métodos modernos de síntese orgânica tem alcançado a área de oligotiofenos e já há relatos sobre a importância de design molecular e de relações estrutura-propriedade para obtenção planejada de oligotiofenos metalocênicos. ${ }^{68} \mathrm{O}$ uso de radiação eletromagnética na região de micro-ondas já foi reportado $0^{69-72}$ para a oligomerização de tiofenos, onde se pode ter a sua preparação - através do acoplamento tipo Suzuky (com paládio) - em grandes quantidades e a obtenção de derivados com aplicações bionanotecnológicas com alta reprodutibilidade e alto nível de pureza (87\%, de 30 a $100 \mathrm{~min})$. Mesmo a moderna fronteira da síntese orgânica, a síntese combinatorial, já vem sendo aplicada para a construção de bancos de dados de compostos conjugados oligoméricos do tipo fenil-tiofenos. ${ }^{73}$

\section{Construção de oligômeros constituídos por mais de uma classe de monômero}

A utilização de diferentes monômeros na constituição de oligômeros tem-se feito presente nos últimos anos. O interessante deste método é a união de propriedades de diferentes materiais em um único, o que resulta em materiais promissores em termos de aplicações tecnológicas. Jaramillo-Isaza e Turner ${ }^{74}$ realizaram a síntese de uma série de oligômeros derivados do tiofeno (24), fluoreno (25), fluorenonas (26) e ciclopentaditiofenona (27) através de acoplamento de Suzuki entre monômeros bromados e derivados borados, utilizando $\mathrm{Pd}\left(\mathrm{PPh}_{3}\right)_{4}$ como catalisador da reação, Figura 11. A partir desta série de derivados, os autores ${ }^{74}$ prepararam estruturas com diferentes combinações, cuja composição estrutural refletiu diretamente nas propriedades ópticas.

Feng e colaboradores ${ }^{75}$ reportaram a obtenção de diversos oligômeros 29a-g incorporando unidades de bis-tienileteno em tiofenos

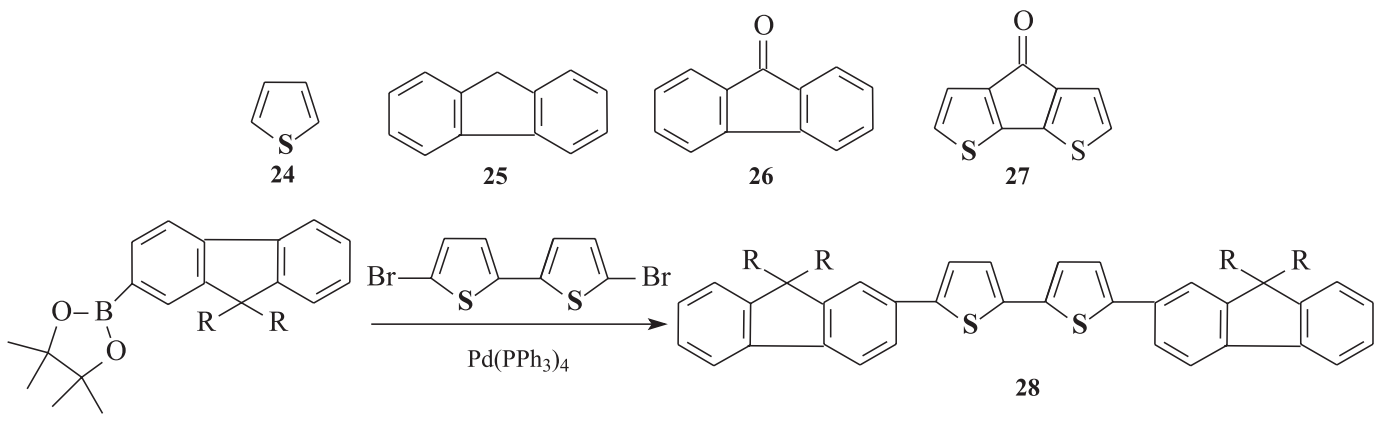

Figura 11. Síntese do 5,5 bis-(9,9-dioctil-9H-fluoren-2-il)-[2,2']bis-tiofeno (28) através do acoplamento de Suzuki utilizando Pd(PPh $)_{4}$ como catalisador ${ }^{74}$ 


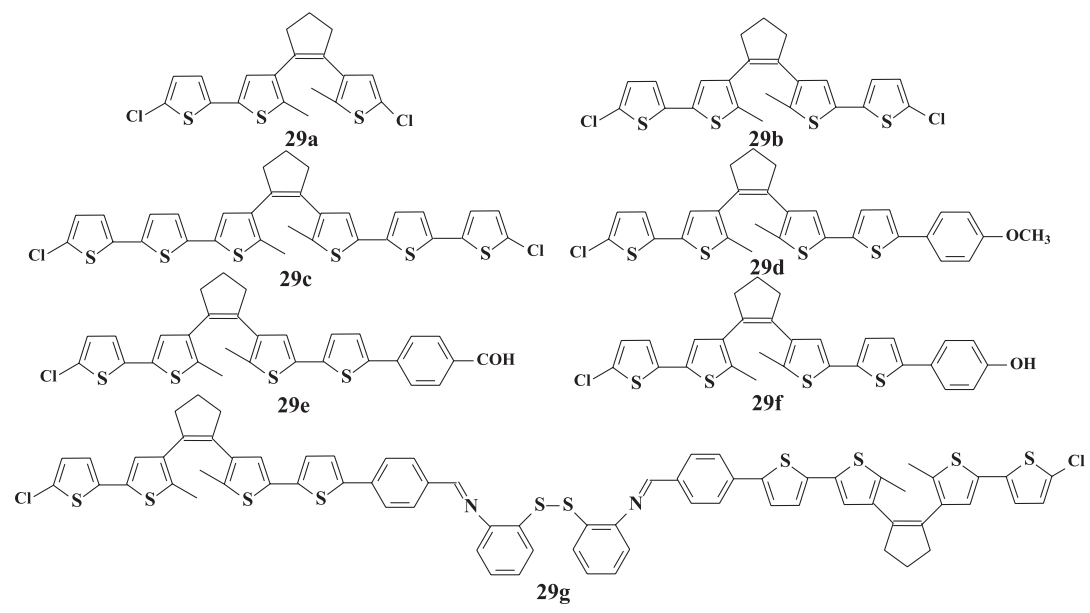

Figura 12. Oligômeros BTEs obtidos por Feng e colaboradores ${ }^{75}$

também através do método de acoplamento de Suzuki (Figura 12). Estes materiais apresentaram boa solubilidade em solventes orgânicos comuns, além de boas propriedades fotocrômicas e boa mobilidade de carga. Sun e colaboradores ${ }^{76}$ realizaram a síntese de calix[4]arenos tetra-oligotiofeno-substituídos (30) (Figura 13) através do método de acoplamento de Kumada, utilizando paládio como catalisador. Os oligômeros $\mathbf{3 0}$ obtidos apresentaram-se com baixo potencial de oxidação e absorção e emissão na região do azul e vermelho, respectivamente.

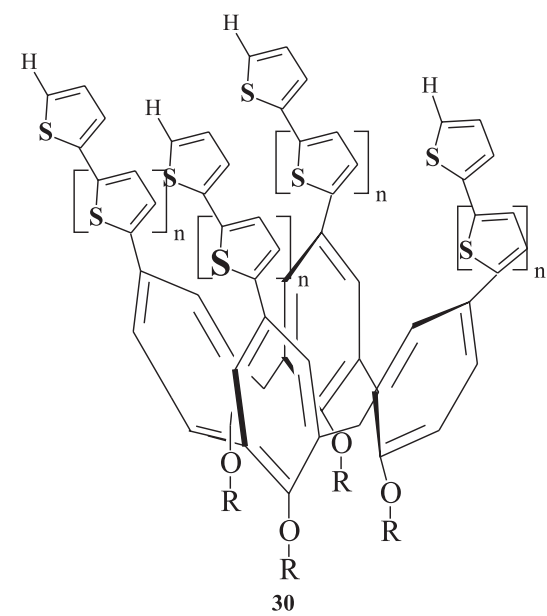

Figura 13. Estrutura química dos calix[4]arenos tetra-oligotiofeno-substituídos 30 obtidos do Sun e colaboradores ${ }^{76}$

Wan e colaboradores ${ }^{77}$ reportaram a obtenção de dímeros de 3-octiltiofeno (31) através de acoplamento oxidativo, utilizando cloreto de cobre como agente oxidante. Em etapa posterior, estes foram empregados na obtenção de diblocos e triblocos de oligômeros. Para a realização dos acoplamentos os autores ${ }^{77}$ utilizaram o acoplamento de Stille. Na Figura 14 é mostrado um exemplo da rota sintética utilizada para a obtenção dos diblocos e triblocos. Os resultados das análises espectroscópicas mostraram que modificando a sequência das unidades de tiofenos e oxadiazol (regioisômeros) ocorrem modificações na Lacuna de Energia $\left(\mathrm{L}_{\mathrm{e}}\right)$ dos oligômeros, podendo ser um eficiente método de se modular a $\mathrm{L}_{\mathrm{e}}$ de oligômeros formados por diferentes classes de monômeros.

Melucci e colaboradores ${ }^{78}$ sintetizaram uma série de novos oligômeros baseados em várias combinações de 3,4-etilenodioxitiofeno (EDOT) (32) com unidades do tiofeno-S,S-dioxido substituído (33) (Figura 15). Os acoplamentos entre os monômeros foram executados também através do método de reação de acoplamento de Stille. A bromação dos oligômeros para as reações de acoplamento foi realizada através do tratamento dos mesmos com N-bromosuccinimida (NBS). Na Figura 15 é possível observar a estrutura de dois dos oligômeros obtidos pelos autores.

\section{POLÍMEROS BASEADOS EM TIOFENOS}

\section{Derivados de tiofenos como polímeros conjugados e algumas de suas aplicações}

Politiofenos e seus derivados, obtidos através de polimerização química ou eletroquímica a partir de seus respectivos monômeros, têm sido alvo de um amplo número de estudos devido às promissoras aplicações. ${ }^{3,5,79}$ Diferentes modificações químicas têm sido realizadas, nos últimos anos, com o intuito de melhorar as propriedades destes polímeros conjugados para satisfazer as diversas características necessárias para aplicações em dispositivos eletrônicos orgânicos ${ }^{80}$ Kabasakaloglu e colaboradores, ${ }^{81}$ em seus estudos das propriedades eletroquímicas de politiofenos, observaram que filmes obtidos eletroquimicamente apresentavam propriedades eletroquímicas e valores de condutância diferentes, dependendo do tipo e concentração do eletrólito suporte em-

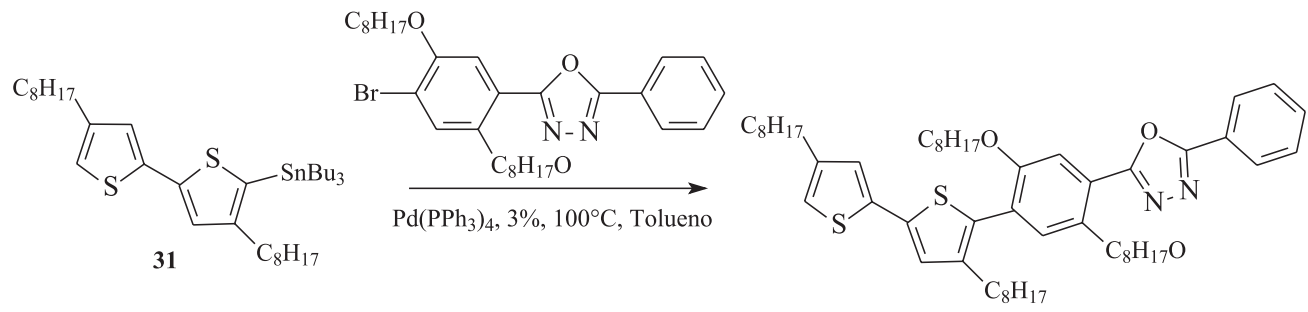

Figura 14. Exemplo de acoplamento de Stille empregado na síntese dos diblocos e triblocos utilizado por Wan e colaboradores ${ }^{77}$ 


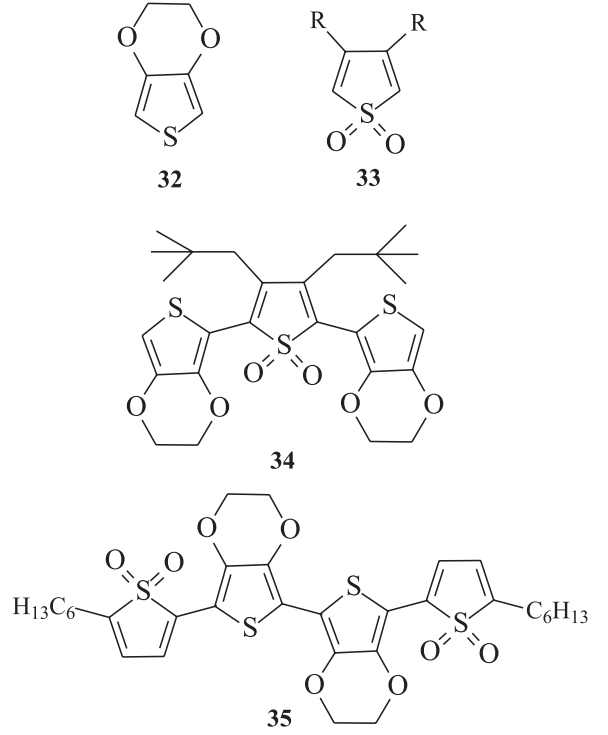

Figura 15. Estrutura química do 3,4-etienedioxitiofeno (EDOT) 32 e substituído tiofeno-S,S-dioxido 33 e de dois oligômeros (34 e 35) gerados da combinação entre 32 e 33 obtidos por Melucci e colaboradores ${ }^{78}$

pregado. As mudanças nas propriedades destes materiais são o resultado das modificações dos estados eletrônicos. Assim, ao modular o estado eletrônico do polímero, podem-se obter materiais com aplicações específicas, relacionadas com suas propriedades eletrônicas/ópticas. Como exemplos, dispositivos optoeletrônicos são elaborados com base nas propriedades eletrônicas/ópticas do material componente..$^{82}$

Polímeros condutores solúveis e processáveis têm sido obtidos através da síntese de oligômeros solúveis, utilizando-se substituintes ou precursores solúveis. Como exemplo, tem-se o polímero poli(isotianafteno) (36) (PITN) (Figura 16) insolúvel e, portanto, não processável, ${ }^{83}$ mas que se tornou solúvel quando os autores adicionaram um grupamento alquila longo na posição 5- do anel monomérico. Em 1987, Patil e colaboradores ${ }^{84}$ reportaram a obtenção dos polímeros conjugados poli(3-tiofeno- $\beta$-etanossulfonato) de sódio (37) (Figura 16) e poli(3-tiofeno- $\delta$-butanossulfonato) de sódio, que se apresentavam solúveis em água. Varis e colaboradores ${ }^{85}$ sin- $^{-}$ tetizaram o polímero poli(1-4-nitrofenil-2,5-di(2-tienil)-1H-pirrol $\mathrm{P}\left(\mathrm{SNSNO}_{2}\right)$ (38) (Figura 16), tanto pelo método químico quanto pelo eletroquímico, que se apresentou solúvel em diversos solventes orgânicos comuns.

Estudos realizados por Ofer e colaboradores ${ }^{86}$ mostraram que politiofenos possuem uma alta condutividade quando são eletroquimicamente oxidados, à temperatura baixa, em $\mathrm{SO}_{2}$ /eletrólito. Mert e colaboradores ${ }^{87}$ realizaram a síntese do monômero difenilditienotiofeno (DPhDTT) (39) (Figura 16) e, em seguida, sua polimerização eletroquímica. Estudos do comportamento espectroeletroquímico do polímero poli(difenilditienotiofeno) $\mathrm{P}(\mathrm{DPhDTT})$ revelaram uma $\mathrm{L}_{\mathrm{e}}$ eletrônica igual a 2,18 eV. Além disso, sobre oxidação o $\mathrm{P}(\mathrm{DPhDTT})$ tem sua cor variada de amarela a cinza. Pang e colaboradores ${ }^{88}$ realizaram a síntese e o estudo das propriedades do poli(3-clorotiofeno) (40) e do poli(3-clorotiofeno-co-3-metiltiofeno) (41) (Figura 16). Seus estudos mostraram que estes polímeros mudavam de cor entre o vermelho e o azul dependendo do nível de oxidação, o que lhes possibilitou afirmar que os mesmos apresentavam potencial aplicativo em dispositivos eletrocrômicos. Esta afirmação pôde ser feita devido ao fato de materiais eletrocrômicos possuírem habilidade de variar reversivelmente sua cor de acordo com o nível de oxidação. ${ }^{89}$

Liu e Gregory ${ }^{90}$ reportaram a síntese de um derivado de po-
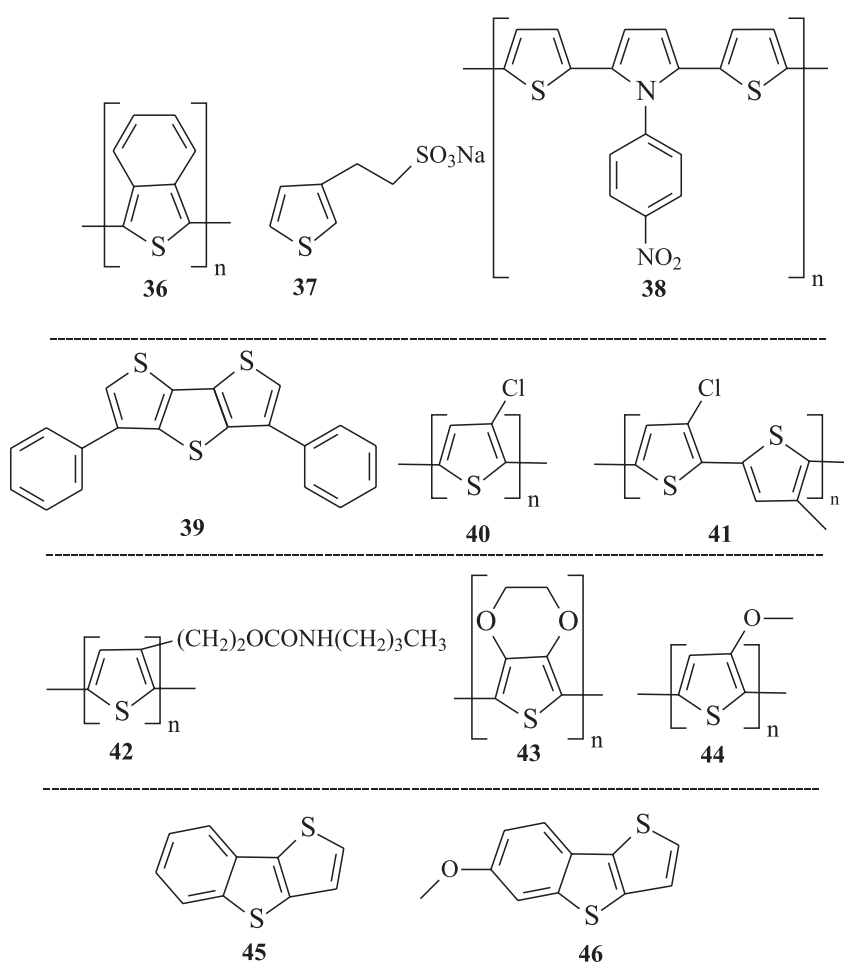

Figura 16. Estruturas químicas de: poli(isotianafteno $)^{83}(36)$, poli(3-tiofeno$\beta$-etanossulfonato) de sódio ${ }^{84}$ (37), poli(1-4-nitrofenil-2,5-di(2-tienil)-1Hpirrol $^{85} \mathrm{P}\left(\mathrm{SNSNO}_{2}\right)$ (38), monômero difenilditienotiofeno ${ }^{87}$ (DPhDTT) (39), poli(3-clorotiofeno $)^{88}(40)$, poli(3-clorotiofeno-co-3-metiltiofeno $)^{88}(41)$, derivado de politiofeno com uretano substituído na posição $\beta$ do anel tiofênico ${ }^{90}$ (42), poli(3,4-etilenodioxitiofeno $)^{91}$ (PEDOT) (43), poli(3-metoxitiofeno $)^{93}$ (44), tieno[3,2-b][1]benzotiofeno ${ }^{95}(T B T)$ (45) e 6-metoxitieno[3,2-b][1]-benzotiofeno95 (MeOTBT) (46)

litiofeno com uretano substituído na posição $\beta$ - do anel tiofênico (42) (Figura 16). O polímero foi obtido através da síntese química empregando-se o cloreto férrico $\left(\mathrm{FeCl}_{3}\right)$ como agente iniciador. Este polímero apresentou boa estabilidade térmica e condutividade variando de 0,08 a $1,4 \mathrm{~S} \mathrm{~cm}^{-1}$, dependendo do nível do dopante.

Um dos polímeros mais estudados devido a sua alta condutividade, sendo considerado o polímero condutor disponível mais estável, é o poli(3,4-etilenodioxitiofeno) (PEDOT) (43), Figura 16. ${ }^{91}$ Os dois átomos de oxigênio adjacentes ao anel tiofênico têm a capacidade, por doação de densidade eletrônica, de estabilizar a carga positiva gerada no processo de oxidação do PEDOT, o que reduz relativamente a $\mathrm{L}_{e}{ }^{92}$ Outro exemplo de polímero condutor que possui sua $\mathrm{L}_{\mathrm{e}}$ influenciada pelo grupo substituinte é o poli(3-metoxitiofeno) (44), Figura 16. Este material tem sido muito estudado devido à presença do oxigênio do grupo alcóxi, que provoca uma diminuição do potencial de oxidação tanto do monômero quanto do polímero, em função do efeito eletrodoador. ${ }^{93,94}$ Pesquisadores como Fouad e colaboradores ${ }^{95}$ têm obtido polímeros através de anéis tiofênicos fundidos. A obtenção dos monômeros tieno[3,2-b][1]benzotiofeno (TBT) (45) e 6-metoxitieno[3,2-b] [1]-benzotiofeno (MeOTBT) (46) foi reportada (Figura 16). Estudos mostram que estes monômeros têm um baixo potencial de oxidação (devido a sua estrutura conjugada). A polimerização eletroquímica destes monômeros foi realizada através de oxidação anódica, resultando na formação de oligômeros de cadeia curta.

Uma forma de controlar as propriedades dos materiais poliméricos para satisfazer as diferentes possibilidades de aplicação tecnológica é através da copolimerização dos monômeros, resultando em um polímero com propriedades intermediárias entre os polímeros individuais. ${ }^{96,97}$ Estes copolímeros são obtidos através da mistura de 


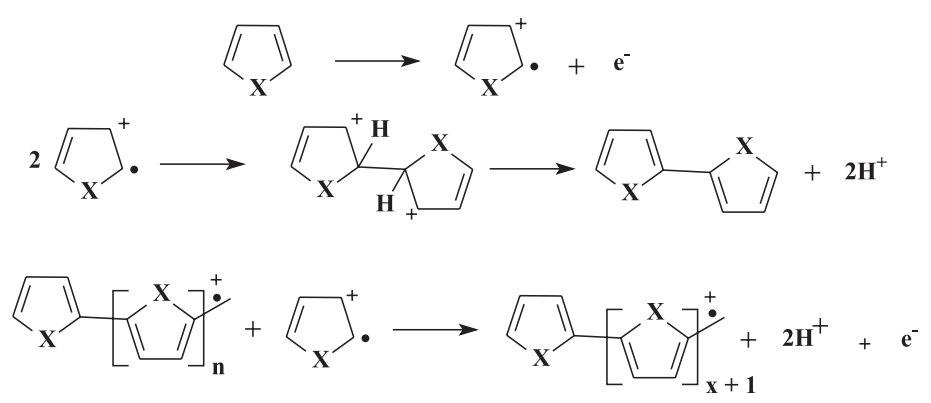

Figura 17. Esquema do mecanismo clássico para a polimerização química ou eletroquímica de monômeros heteroaromáticos de 5 membros ${ }^{16}$

dois ou mais monômeros e, em seguida, realiza-se a polimerização química ou eletroquímica.

\section{MÉTODOS USUAIS DE OBTENÇÃO DE POLITIOFENOS}

\section{Síntese química de politiofenos}

A síntese química desta classe de polímeros é comumente realizada através de polimerização radicalar, que é o resultado da oxidação do monômero (formando íons radicais) através de um agente iniciador (agente oxidante) e posterior acoplamento dos monômeros, passando pelas etapas de iniciação, propagação e finalização (Figura 17). ${ }^{16}$

A polimerização química mais utilizada emprega haletos metálicos como agente iniciador, sendo o cloreto férrico o mais utilizado com razão molar 4:1 ( $\mathrm{FeCl}_{3}$ :monômero) sob atmosfera inerte..$^{98-105}$

Politiofenos e derivados também podem ser obtidos através do acoplamento de Grignard (tipo Kumada), realizado a partir de monômeros 2,5-di-halogeniotiofeno 47 e derivados como mostrado na Figura 18. ${ }^{3}$ Pomerantz e colaboradores ${ }^{106}$ obtiveram polímeros derivados de tiofenos (dibromo-ésteres) através da reação de acoplamento de Ullmann, utilizando três equivalentes de cobre metálico em DMF, porém esta reação teve um tempo relativamente alto (7 dias), o que leva à conclusão de que o método oxidativo com $\mathrm{FeCl}_{3}$ apresenta bons resultados com relação ao tempo de reação (cerca de algumas horas, tendo um máximo reportado de $24 \mathrm{~h}$ por alguns autores ${ }^{107}$ ).

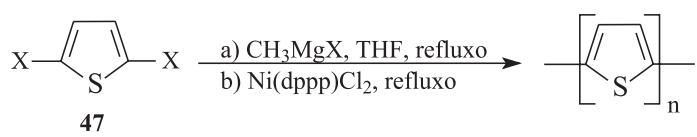

Figura 18. Esquema da polimerização do tiofeno via acoplamento de Grignard $^{3}$

O poli(3-metoxitiofeno) (PMOT) (44) pode ser obtido a partir da polimerização química através da oxidação do monômero 3-metoxitiofeno com o cloreto férrico, sob atmosfera de nitrogênio. Hu e $\mathrm{Xu}^{93}$ realizaram a síntese química à baixa temperatura $\left(0^{\circ} \mathrm{C}\right)$ de vários poli(alcoxitiofenos) incluindo o PMOT e obtiveram compostos com considerável massa molecular em um tempo significativamente curto de reação (2 h), o que é muito atrativo já que outros pesquisadores relatam reações que tiveram duração de $24 \mathrm{~h}$ à temperatura ambiente. ${ }^{107}$ Copolímeros podem também ser obtidos através da formação de íons radicais empregando-se $\mathrm{FeCl}_{3}$ como agente iniciador. ${ }^{108}$

O poli(3-tiofenoetanol) (48) pode ser obtido através de duas rotas: (a') realiza-se a esterificação do monômero 3-tiofenoetanol, (a") polimerização utilizando o cloreto férrico como agente oxidante e (a"') uma reação de saponificação ${ }^{109} \mathrm{ou}$ (b) através da polimerização química direta do 3-tiofenoetanol com $\mathrm{FeCl}_{3}$, como relatado por Philip e colaboradores. ${ }^{110} \mathrm{~A}$ rota (a) é mais aconselhada, pois assim impede-se que o grupo hidroxila atue como um nucleófilo no decorrer da polimerização. A Figura 19 mostra as duas rotas sintéticas para a obtenção do polímero $\mathbf{4 8}$ através de síntese química.

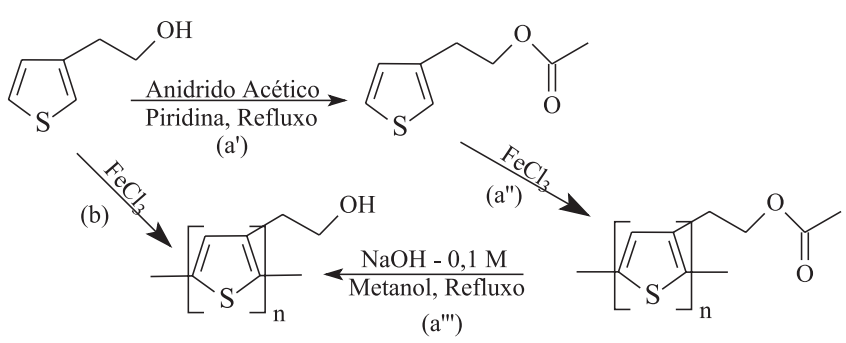

48

Figura 19. Obtenção do poli(3-tiofenoetanol) via polimerização química ${ }^{109,110}$

Apesar do método de polimerização utilizando $\mathrm{FeCl}_{3}$ como agente oxidante ser um método simples, o fato de o produto final apresentar defeitos regioquímicos significativos fez com que diversos pesquisadores se dedicassem ao desenvolvimento de metodologias em que se pudesse ter materiais com acoplamentos controlados, contudo, podem-se obter materiais regiorregulares através desta metodologia. ${ }^{99}, 105$ De acordo com Andersson e colaboradores, ${ }^{111}$ os tiofenos $\beta$-substituídos podem acoplar de três formas diferentes: cabeça-cabeça (Head-Head, HH), cauda-cauda (Tail-Tail, TT) e cabeça-cauda (Head-Tail, HT). A Figura 20 mostra as possíveis regiorregularidades para o acoplamento de dois monômeros derivados do tiofeno $\beta$-substituídos. Com o intuito de melhorar a regiorregularidade de oligômeros e polímeros, McCullough e Lowe ${ }^{112}$ reportaram a obtenção de polímeros de alquiltiofeno através da adição de lítio na posição 5- de um 3-alquiltiofeno, seguido de troca deste metal por um composto de Grignard, que foi polimerizado através de acoplamentos catalisados por $\mathrm{Ni}(\mathrm{dppp}) \mathrm{Cl}_{2}$ (tipo Kumada).

Chen e Rieke ${ }^{113}$ descreveram a obtenção de poli(3-hexiltiofenos) regiorregulares através da reação entre o 2,5-dibromo-3-hexiltiofeno e $\mathrm{Zn}$ altamente reativo, gerando 2-bromo-5-bromozinco-3-hexiltiofeno que, em seguida, foi polimerizado utilizando-se $\mathrm{Ni}$ (dppe) $\mathrm{Cl}_{2}$ como catalisador (acoplamento tipo Negishi). Outro método que possibilita obter polímeros de oligômeros contendo tiofenos foi apresentado por Egbe e colaboradores, ${ }^{114}$ sendo o polímero obtido através da reação do monômero e terc-butóxido de potássio em solução de tolueno sob refluxo.

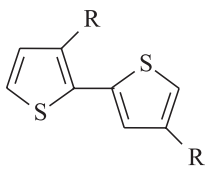

H-T

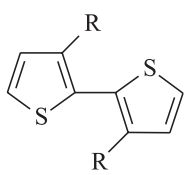

$\mathrm{H}-\mathrm{H}$

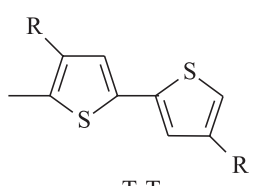

T-T
Figura 20. Possíveis regiorregularidades de acoplamento entre dois monômeros derivados do tiofeno $\beta$-substituído ${ }^{111}$ 


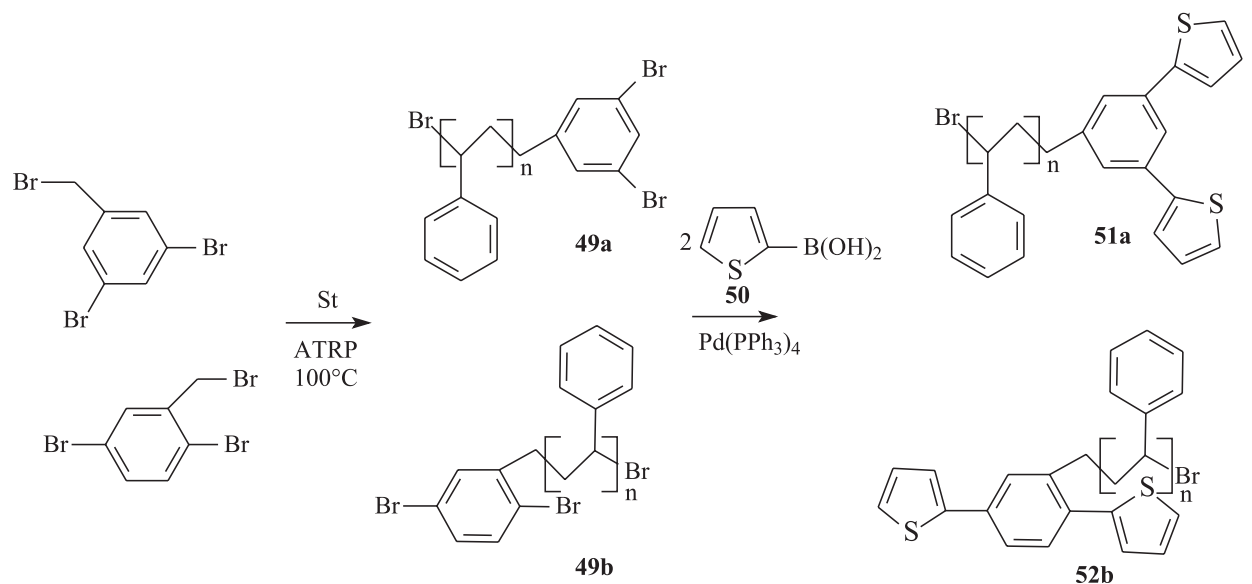

Figura 21. Síntese de macromonômeros 51 a e 51 b a partir da reação de acoplamento entre poliestirenos bromados 49 a e 49b e tiofeno 3-borânico substituído (50) $)^{128}$

\section{Síntese eletroquímica de politiofenos}

Para a obtenção desta classe de polímeros e diversas outras é costumeiramente empregada a síntese eletroquímica, que oferece várias vantagens em relação à rapidez e produção direta de polímeros em eletrodos, tanto no estado dopado como não dopado. ${ }^{4,115}$ As condições em que estes materiais são eletrossintetizados influenciam diretamente nas propriedades elétricas e físico-químicas do material final. Diante disto, a concentração do monômero, temperatura e natureza do meio eletrolítico são alguns dos parâmetros que devem ser determinados para a obtenção de polímeros com propriedades satisfatórias. ${ }^{116}$

Alguns monômeros, por apresentarem dificuldades de síntese eletroquímica, necessitam passar por transformações químicas, para se obter compostos mais reativos. O 3-tiofenoetanol é um exemplo de monômero que apresenta baixa probabilidade de eletropolimerização direta do monômero, devido apresentar a forma oxidada propensa a ataques nucleofílicos nas posições 3- e 4-, sendo que o papel de nucleófilo pode ser assumido por outro monômero, levando à obtenção de compostos acoplados não eletroativos. ${ }^{117}$ Uma alternativa para se obter o polímero deste monômero é através da realização da proteção do grupo hidroxila por esterificação. Assim, polimeriza-se o éster obtido e, em seguida, realiza-se uma reação de saponificação para provocar a desproteção do grupo hidroxila.

A eletropolimerização dos monômeros é realizada em célula eletroquímica convencional, com uma configuração de três eletrodos. Os monômeros são dissolvidos em solvente adequando numa concentração que varia de acordo com a facilidade do monômero em sofrer polimerização, contendo um eletrólito suporte numa concentração de $0,1 \mathrm{~mol} \mathrm{~L}^{-1}$. As técnicas eletroquímicas utilizadas para a realização das polimerizações são cronopotenciometria ${ }^{118} \mathrm{e}$ cronoamperometria ${ }^{87,119-121} \mathrm{e}$, a técnica mais comum, a voltametria cíclica. ${ }^{7,19,95,122-127}$

A polimerização através da técnica de voltametria cíclica consiste em escolher uma faixa de potencial na qual o potencial máximo de oxidação do monômero esteja incluído e o potencial varia com uma determinada velocidade de varredura. A aplicação de um potencial constante igual ou superior ao potencial de oxidação do monômero por um determinado tempo resulta na formação de filmes finos de polímeros; esta técnica é denominada cronoamperometria. Polímeros obtidos por aplicação de uma corrente constante são resultado da técnica cronopotenciometria.

Como último exemplo de síntese de politiofenos, cabe relatar o interessante estudo de Toppare e colaboradores ${ }^{128}$ onde um método sintético misto (Figura 21) foi aplicado: poliestirenos recém-sintetizados por polimerização radicalar (49a e 49b) foram submetidos à reação (acoplamento de Suzuki) com ácido 3-borônico tiofênico (50) gerando polímeros funcionalizados quimicamente, ou macromonômero (51a e 51b), que foi eletropolimerizado para geração de copolímeros com alta estabilidade e diferente comportamento espectroeletroquímico.

\section{CONSIDERAÇÕES FINAIS}

Com a descoberta de que materiais orgânicos conjugados, principalmente os politiofenos, tinham propriedades elétricas interessantes e que estas propriedades melhoravam com o aumento da conjugação, houve um crescimento considerável, desde os anos 80 , na busca de oligômeros de tiofenos cada vez maiores e com acoplamentos regulares que possibilitassem a manutenção da conjugação. Com a observação de que o aumento da cadeia oligomérica era limitado pela diminuição da solubilidade ocorreu uma segunda transição, passa-se a se utilizar materiais precursores com grupos alquilas que, por sua vez, favorecem a solubilidade dos materiais finais.

Diversas metodologias de síntese de oligômeros e polímeros de tiofeno foram desenvolvidas e são utilizadas largamente nos dias atuais, principalmente a partir de reações clássicas de acoplamento com organometálicos (tipos Heck, Kumada, Negishi, Stille, Sukuki e Ullmann), reações de acoplamento oxidativo, polimerização com agentes oxidantes e síntese de polímeros diretamente na superfície de eletrodos (eletropolimerização). Entretanto, por exemplo, há diversas metodologias de acoplamento tipo Suzuki recentemente descritas que ainda não foram investigadas na síntese de oligotiofenos ou politiofenos, tais como a síntese de di-tiofenos não simétricos; ${ }^{129}$ a descrição de acoplamento em meio aquoso e sem a necessidade de complexos de paládio, mas só paládio coloidal $(1 \%) ;{ }^{130}$ síntese em meio aquoso com irradiação por micro-ondas ( $1 \mathrm{mmol}$ de haleto de arila e $2,5 \mathrm{ppm}$ de $\mathrm{Pd}$, minutos de reação $)^{131}$ e a formação de intermediários borânicos sem a passagem pelo precursor haleto-substituído. ${ }^{132}$ Investigações destas novas rotas de acoplamento podem gerar interessantes e promissoras linhas de pesquisa interdisciplinar visando a obtenção de métodos mais eficientes para síntese destes importantes derivados de oligotiofenos e politiofenos.

A necessidade da obtenção de PCs com boa estabilidade térmica, boa processabilidade e com melhor controle da Lacuna de energia $\left(\mathrm{L}_{\mathrm{e}}\right.$ ) são os objetivos das pesquisas nesta área. Diversos pesquisadores, ainda hoje, são estimulados a obter sinteticamente oligo- e poli-tiofenos com características e propriedades específicas, utilizando-se da habilidade interdisciplinar para a construção de moléculas especiais. 


\section{AGRADECIMENTOS}

À FAPEMIG (PRONEX EDT 479/07; PPM III 0207/09; CEX APQ-01621-09) e ao CNPq pelo apoio financeiro.

\section{REFERÊNCIAS}

1. MacDiarmid, A. G.; Chemistry in New Zealand 2001, 65, 8.

2. Beaujuge, P. M.; Reynolds, J. R.; Chem. Rev. 2010, 110, 268.

3. Hou, J.; Huo, L.; He, C.; Yang, C., Li, Y.; Macromolecules 2006, 39, 594.

4. Pang, Y., Li, X., Ding, H.; Shi, G.; Jin, L.; Electrochim Acta 2007, 52, 6172.

5. Liesa, F.; Ocampo, C.; Alemán, C.; Armelin, E.; Oliver, R.; J. Appl. Polym. Sci. 2006, 102, 1592.

6. Ocampo, C.; Armelin, E.; Liesa, F.; Alemán, C.; Ramis, X.; Iribarren, J. I.; Prog. Org. Coat. 2005, 53, 217.

7. Sotzing, G. A.; Reynolds, J. R.; Steel, P. J.; Chem. Mater. 1996, 8, 882.

8. Li, F.; Albery, W. J.; J. Electroanal. Chem. 1991, 302, 279.

9. Monk, P. M. S.; Mortimer, R. J.; Rosseinsky, D. R.; Electrochromism and Electrochromic Devices, Cambridge University Press: Cambridge, 2007.

10. Dyer, A. L.; Reynolds, J. R. Em Handbook of Conducting Polymers; Skotheim, T. A.; Reynolds, J. R., eds.; $3^{\text {rd }}$ ed.; CRC Press: Boca Raton, 2007.

11. Walton, D. J.; Davis, F. J.; Langley, P. J.; Polymer Chemistry 2004, 158.

12. Garnier, F.; Tourillon, G.; Gazard, M.; Dubois, J. C.; J. Electroanal. Chem. 1983, 148, 299.

13. Gazard, M.; Dubois, J. C.; Champagne, M.; Garnier, F.; Tourillon, G.; J. Phys., Colloq. 1983, 44, 537.

14. Druy, M. A.; Seymour, R. J.; Org. Coat. Appl. Polym. Sci. Proc. 1983, 48,561 .

15. Druy, M.; Seymour, R.; J. Phys., Colloq. 1983, 44, 595.

16. Roncali, J.; Chem. Rev. 1992, 92, 711.

17. Roncali, J.; Chem. Rev. 1997, 97, 173.

18. Tepavcevic, S.; Wroble, A. T.; Bissen, M.; Wallace, D. J.; Choi, Y.; Hanley, L.; J. Phys. Chem. B 2005, 109, 7134.

19. Sankaran, B.; Reynolds, J. R.; Macromolecules 1997, 30, 2582.

20. Neves, S.; Gazotti, W. A.; De Paoli, M.-A. Em Encyclopedia of Nanoscience and Nanotechnology; Nalwa, H. S., ed.; American Scientific Publishers: Valencia, 2004, vol. 2, p. 133-152.

21. Blanchard, P.; Cravino, A.; Levillain, E. Em Handbook of ThiopheneBased Materials; Perepichka, I. F.; Perepichka, D. F., eds.; Wiley: New York, 2009, cap. 4.

22. Skabara, P. J. Em ref. 21, cap. 3.

23. Mishra, A.; Ma, C.-Q.; Segura, J. L.; Bauerle, P. Em ref. 21, cap. 1.

24. Facchetti, A. Em ref. 21, cap. 16.

25. Blanchard, P.; Leriche, P.; Frere, P.; Roncali, J. Em Handbook of Conducting Polymers; Terje, A. S.; Reynolds, J., eds.; $3^{\text {rd }}$ ed.; CRC Press: Boca Raton, 2007, vol. 1.

26. Katz, H. E.; Dodabalapur, A.; Bao, Z. Em Handbook of Oligo- and Polythiophenes; Fichou, D., ed.; Wiley: New York, 1999, cap. 9.

27. McCullough, R. D. Em ref. 26, cap. 1.

28. McCullough, R. D.; Adv. Mater. (Weinheim, Ger) 1998, 10, 93.

29. Pron, A.; Barta, P.; Luzny, W.; Niziol, J.; Condensed Matter News 1997, $6,13$.

30. Higgins, S. J.; Chem. Soc. Rev. 1997, 26, 247.

31. Mortimer, R. J.; Chem. Soc. Rev 1997, 26, 147.

32. Bauerle, P. Em ref. 26, cap. 3.

33. Andersson, M. R.; Thomas, O.; Mammo, W.; Svensson, M.; Theander, M.; Inganas, O.; J. Mater. Chem.1999, 9, 1933.

34. Roncali, J.; Acc. Chem. Res. 2000, 33, 147.

35. Pearson, D. L.; Jones, L.; Schumm, J. S.; Tour, J. M.; Synth. Met. 1997, $84,303$.

36. Li, Y.; Current Trends in Polymer Science 2002, 7, 101.
37. Toshima, N.; Hara, S.; Prog. Polym. Sci. 1995, $20,155$.

38. Chan, H. S. O.; Ng, S. C.; Prog. Polym. Sci. 1998, 23, 1167.

39. Anctil, E. J.-G.; Snieckus, V.; Metal-Catalyzed Cross-Coupling Reactions 2004, 2, 761.

40. Kurti, L.; Czako, B.; Strategic Applications of Named Reactions in Organic Synthesis, $1^{\text {st }}$ ed.; Skotheim, T. A.; Reynolds, J., eds.; Academic Press: California, 2005.

41. Babudri, F.; Farinola, G. M.; Naso, F.; Synlett 2009, 17, 2740.

42. Yamamoto, T.; J. Organomet. Chem. 2002, 653, 195.

43. Nakayama, J.; Konishi, T.; Hoshino, M.; Heterocycles 1988, $27,173$.

44. Hotta, O.; Molecular Electronics and Bioelectronics 2001, 12, 20.

45. Otsubo, T.; Aso, Y.; Kagaku Furontia 2002, 6, 93.

46. Lukevics, E.; Arsenyan, P.; Pudova, O.; Heterocycles 2003, 60, 663.

47. Zotti, G.; Schiavon, G.; Chem. Mater. 1993, 5, 430.

48. Meisel, S. L.; Johnson, G. C.; Hartough, H. D.; J. Am. Chem. Soc. 1950, $72,1910$.

49. Gommers, F. J.; Nematologica 1972, 18, 458.

50. Chan, G. F. Q.; Towers, G. H. N.; Mitchell, J. C.; Phytochemistry 1975 , 14, 2295.

51. Beny, J. P.; Dhawan, S. N.; Kagan, J.; Sundlass, S.; J. Org. Chem. 1982, 47, 2201.

52. Kagan, J.; Arora, S. K.; J. Org. Chem. 1983, $48,4317$.

53. Kagan, J.; Arora, S. K.; Tetrahedron Lett. 1983, 24, 4043.

54. Tamao, K.; Kodama, S.; Nakajima, I.; Kumada, M.; Tetrahedron 1982, $38,3347$.

55. Carpita, A.; Rossi, R.; Veracini, C. A.; Tetrahedron 1985, 41, 1919.

56. Zhao, M. T.; Singh, B. P.; Prasad, P. N.; J. Chem. Phys. 1988, 89, 5535.

57. Wang, D. L.; Hwang, W. S.; J. Organomet. Chem. 1991, 406, c29.

58. Katz, H. E.; Torsi, L.; Dodabalapur, A.; Chem. Mater. 1995, 7, 2235.

59. Sone, T.; Umetsu, Y.; Sato, K.; Bull. Chem. Soc. Jpn. 1991, 64, 824.

60. Tour, J. M.; Wu, R.; Macromolecules 1992, 25, 1901.

61. ten Hoeve, W.; Wynberg, H.; Havinga, E. E.; Meijer, E. W.; J. Am. Chem. Soc. 1991, 113, 5887.

62. Hassan, J.; Gozzi, C.; Schulz, E.; Lemaire, M.; J. Organomet. Chem. 2003, 687, 80 .

63. Roncali, J.; Thobie-Gautier, C.; Elandaloussi, E. H.; Frère, P.; J. Chem. Soc., Chem. Commun. 1994, 2249.

64. Bukalov, S. S.; Leites, L. A.; Lyssenko, K. A.; Aysin; R. R.; Korlyukov A. A.; Zubavichus, J. V.; Chernichenko, K. Y.; Balenkova, E. S.; Nenajdenko, V. G.; Antipin, M. Yu.; J. Phys. Chem. A 2008, 112, 10949.

65. Krömer, J.; Rios-Carreras, I.; Fuhrmann, G.; Musch, C.; Wunderlin, M.; Debaerdemaeker, T.; Mena-Osteritz, E.; Bäuerle, P.; Angew. Chem., Int. Ed. 2000, 39, 3481.

66. Roncali, J.; Chem. Soc. Rev. 2005, 34, 483.

67. Roman, L. S.; Optical Science and Engineering 2005, 99, 367.

68. Wong, W. Y.; Comments Inorg. Chem. 2005, 26, 39.

69. Melucci, M.; Barbarella, G.; Targets in Heterocyclic Systems 2008, 12, 460.

70. Bhattacharya, S.; Srivastavaa, A.; Sengupta, S.; Tetrahedron Lett. 2005 , 46, 3557.

71. Arvela, R. K.; Leadbeater, N. E., Mack, T. L.; Kormos, C. M.; Tetrahedron Lett. 2006, 47, 217.

72. Chanthavong, F.; Leadbeater, N. E.; Tetrahedron Lett. 2006, 47, 1909.

73. Briehn, C. A.; Schiedel, M.-S.; Bonsen, E. M.; Schuhmann, W.; Bauerle, P.; Angew. Chem., Int. Ed. 2001, 40, 4680.

74. Jaramillo-Isaza, F.; Turner, M. L.; J. Mater. Chem. 2006, 16, 83.

75. Feng, Y.; Yan, Y.; Wang, S.; Zhu, W.; Qian, S.; Tian, H.; J. Mater. Chem. 2006, 16, 3685 .

76. Sun, X. H.; Chan, C. S.; Wong, M. S.; Wong, W. Y.; Tetrahedron 2006, 62,7846 .

77. Wan, J. H.; Feng, J. C.; Wen, G. A.; Wei, W.; Fan, Q. L.; Wang, C. M.; Wang, H. Y.; Zhu, R.; Yuan, X. D.; Huang, C. H.; Huang, W.; J. Org. Chem. 2006, 71, 2565. 
78. Melucci, M.; Frere, P.; Allain, M.; Levillain, E.; Barbarella, G.; Rancoli, J.; Tetrahedron 2007, 63, 9774.

79. Fall, M.; Diagne, A. A.; Dieng, M. M.; Deflorian, F.; Rossi, S.; Bonora, P. L.; Volpe, C. D.; Aaron, J.; J. Synth. Met. 2005, 155, 569.

80. Tan, Z.; Zhou, E.; Yang, Y.; He, Y.; Yang, C.; Li, Y.; Eur. Polym. J. 2007, $43,855$.

81. Kabasakaloglu, M.; Kiyak, T.; Toprak, H.; Aksu, M. L.; Appl. Surf. Sci. 1999, 152, 115.

82. Lee, H. J.; Park, S.; J. Phys. Chem. B 2004, 108, 16365.

83. Chen, S.; Lee, C.; Polymer 1996, 37, 519.

84. Patil, A. O.; Ikenoue, Y.; Wudl, F.; Heeger, A. J.; J. Am. Chem. Soc. 1987, 109, 1858.

85. Varis, S.; Ak, M.; Tanyeli, C.; Akhmedov, I. M.; Toppare, L.; Eur. Polym. J. 2006, 42, 2352.

86. Ofer, D.; Crooks, R. M.; Wrighton, M. S.; J. Am. Chem. Soc. 1990, 112, 7869.

87. Mert, O.; Sahin, E.; Ertas, E.; Ozturk, T.; Aydin, E. A.; Toppare, L.; J. Electroanal. Chem. 2006, 591, 53.

88. Pang, Y.; Xu, H.; Li, X.; Ding, H.; Cheng, Y.; Shi, G.; Jin, L.; Electrochem. Commun. 2006, 8, 1757.

89. Sotzing, G. A.; Reynolds, J. R.; Steel, P. J.; Chem. Mater. 1996, 8, 882.

90. Liu, M.; Gregory, R.; Synth. Met. 1995, 72, 45.

91. Liesa, F.; Ocampo, C.; Alemán, C.; Armelin, E.; Oliver, R.; J. Appl. Polym. Sci. 2006, 102, 1592.

92. Oliver, R.; Munoz, A.; Ocampo, C.; Alemán, C.; Armelin, E.; Estrany, F.; Chem. Phys. 2006, 328, 299.

93. Hu, X.; Xu, L.; Polymer 2000, 41, 9147.

94. Cihaner, A.; Onal, A. M.; J. Electroanal. Chem. 2007, 601, 68.

95. Fouad, I.; Mechbal, Z.; Chane-Ching, K. I.; Adenier, A.; Maurel, F.; Aaron, J. J.; Vodicka, P.; Cernovska, K.; Kozmik, V.; Svoboda, J.; J. Mater. Chem. 2004, 14, 1711.

96. Oliver, R.; Munoz, A.; Ocampo, C.; Alemán, C.; Armelin, E.; Estrany, F.; Chem. Phys. 2006, 328, 299.

97. Alves, M. R. A.; Calado, H. D. R.; Donnici, C. L.; Matencio, T.; Synth. Met. 2010, 160, 22.

98. Chen, S. A.; Tsai, C. C.; Macromolecules 1993, 26, 2234.

99. Andersson, M. R.; Selse, D.; Berggren, M.; Jarvinen, H.; Hjertberg, T.; Inganas, O.; Wennerstrom, O.; Osterholm, J. E.; Macromolecules 1994, $27,6503$.

100. Bizzarri, P. C.; Andreani, F.; Casa, C. D.; Lanzi, M.; Salatelli, E.; Synth. Met. 1995, 75, 141.

101. Hirota, N.; Hisamatsu, N.; Maeda, S.; Tsukahara, H.; Hyodo, K.; Synth. Met. 1996, 80, 67.

102. Hong, X.; Tyson, J. C.; Middlecoff, J. S.; Collard, D. M.; Macromolecules 1999, 32, 4232.

103. Ganapathy, H. S.; Kim, J. S.; Jin, S. H.; Gal, Y. S.; Lim, K. T.; Synth. Met. 2006, 156, 70.

104. Patrício, P. S. O.; Calado, H.D.R.; Oliveira, F. A. C.; Righi, A.; Neves, B. R. A.; Silva, G. G.; Cury, L.; J. Phys.: Condens. Matter. 2006, 18, 7529.

105. Calado, H. D. R.; Matencio, T.; Donnici, C. L.; Cury, L. A.; Rieumont, J.; Pernaut, J. M.; Synth. Met. 2008, 158, 1037.
106. Pomerantz, M.; Cheng, Y.; Kasim, R. K.; Elsenbaumer, R. L.; J. Mat. Chem. 1999, 9, 2155.

107. Daoust, G.; Leclerc, M.; Macromolecules 1991, 24, 455.

108. Casa, D. C.; Fraleoni-Morgera, A.; Lanzi, M.; Costa-Bizzarri, P.; Paganin, L.; Bertinelli, F.; Schenetti, L.; Mucci, A.; Casalboni, M.; Sarcinelli, F.; Quatela, A.; Eur. Polym. J. 2005, 41, 2360.

109. Lowe, J.; Holdcroft, S.; Macromolecules 1995, 28, 4608.

110. Philip, B.; Xie, J.; Chandrasekhar, A.; Abraham, J.; Varadan, V. K.; Smart Mater. Struct. 2004, 13, 295.

111. Andersson, M. R.; Thomas, O.; Mammo, W.; Svensson, M.; Theander, M.; Ingana, O.; J. Mater. Chem. 1999, 9, 1933.

112. McCullough, R. D.; Lowe, R. D.; J. Chem. Soc., Chem. Commun. 1992, 70 .

113. Chen, T. A.; Rieke, R. D.; J. Am. Chem. Soc. 1992, 114, 10087.

114. Egbe, D. A. M.; Nguyen, L. H.; Carbonnier, B.; Muhlbacher, D.; Sariciftci, N. S.; Polymer 2005, 46, 9585.

115. Latonen, R. M.; Lonnqvist, J. E.; Jalander, L.; Ivaska, A.; Electrochim. Acta 2006, 51, 1244.

116. Maia, D. J.; De-Paoli, M. A.; Alves, O. L.; Zarbin, A. J.; Neves, S.; Quim. Nova 2000, 23, 204.

117. Dass, A.; Mulik, S.; Sotiriou-Leventis, C.; Leventis, N.; Synth. Met. 2006, $156,966$.

118. Tang, H.; Zhou, Z.; Zhong, Y.; Liao, H.; Zhu, L.; Thin Solid Films 2006, 515, 2447.

119. Blankespoor, R. L.; Miller, L. L.; J. Chem. Soc., Chem. Commun. 1985, 90.

120. Pohjakallio, M.; Sundholm, G.; Synth. Met. 1993, 55-57, 1590.

121. Sahin, E.; Camurlu, P.; Toppare, L.; Mercore, V. M.; Cianga, I.; Yagci, Y.; J. Electroanal. Chem. 2005, 579, 189.

122. Ballarin, B.; Seeber, R.; Tonelli, D.; Andreani, F.; Bizzarri, P. C.; Casa, C. D.; Salatelli, E.; Synth. Met. 1997, 88, 7.

123. Welzel, H. P.; Kossmehl, G.; Boettcher, H.; Engelmann, G.; Hunnius, W. D.; Macromolecules 1997, 30, 7419.

124. Ribeiro, A. S.; Jr, W. A. G.; Filho, P. F. S.; De Paoli, M. A.; Synth. Met. 2004, 145,43

125. Dang, X. D.; Intelmann, C. M.; Rammelt, U.; Plieth, W.; J. Solid State Electrochem. 2005, 9, 706.

126. Moskma, T.; Domagala, W.; Czarddybon, A.; Pilawa, B.; Lapkowski, M.; Synth. Met. 2005, 152, 189.

127. Zykwinska, A.; Domagala, A.; Czardybon, A.; Pilawa, B.; Lapkowski, M.; Electrochim. Acta 2006, 51, 2135.

128. Sahin, E.; Camurlu, P.; Toppare, L.; Mercore, V. M.; Cianga, I.; Yagci, Y.; J. Electroanal. Chem. 2005, 579, 189.

129. Yokooji, A.; Satoh, T.; Miura, M.; Nomura, M.; Tetrahedron 2004, 60, 6757.

130. Bhattacharya, S.; Srivastava, A.; Sengupta, S.; Tetrahedron Lett. 2005, 46, 3557.

131. Arvela, R. K.; Leadbeater, N. E.; Mack, T. L.; Chad, M.; Kormos, C. M.; Tetrahedron Lett. 2006, 47, 217.

132. Mertins, K.; Zapf, A.; Beller, M.; J. Mol. Catal. A: Chem. 2004, 207, 21. 